\title{
perifèria
}

Número 9, Diciembre 2008

www.periferia.name

\section{Uns déus entre els homes: Món còsmic i món social a la vall de Kullu, Índia}

Alice Van den Bogaert - Departament d'Antropologia Social i Cultural (UAB)1

\begin{abstract}
Resum
La possessió a la Índia, considerada com un fenomen marginal per als indianistes, ha estat un tema d'estudi deixat de banda durant molt de temps. Diverses obres mostren, això no obstant, que les possessions divines o nefastes es troben sobre tot el territori indi. La meva investigació està dirigida a estudiar la relació entre el sistema de possessió institucional i el sistema de castes, i analitza més particularment la construcció de l'organització social i de la cosmologia en una regió de l'Himalàia indi. En aquest article parlarem de la possessió i de les divinitats locals, particularment de la relació entre el món social i el món còsmic des d'aquesta perspectiva.
\end{abstract}

Paraules clau: Cosmologia; possessió; sistema de castes; organització social; Índia.

\begin{abstract}
In India, the possession, considered as a marginal phenomenon by the indianists, has been a study subject forgotten for a long time. However, many studies show that divine or harmful possessions appear all over the Indian territory. Our research is based on the relationship between the institutional possession system and the caste system, analysing in particular the social organization and the cosmology in an Indian Himalaya region. In this article, we will talk about the local divinities and possessions, by studying the relationship between the social world and the cosmic world.
\end{abstract}

Keywords: Cosmology; possession; caste system; social organization; India.

La possessió a la Índia, considerada com un fenomen marginal per als indianistes, ha estat un tema d'estudi deixat de banda durant molt de temps (Tarabout i Assayag 1999). Diverses obres mostren, això no obstant, que les possessions divines o nefastes ${ }^{2}$ es troben sobre tot el territori indi (Tarabout i Assayag 1999;

\footnotetext{
${ }^{1}$ Enviar correspondencia a: alice_vdb@hotmail.com

2 És a dir possessions per déus o per esperits.
} 


\section{perifèria}

Número 9, Diciembre 2008

www.periferia.name

Berti 2001; Vidal 1989). La meva investigació està dirigida a estudiar la relació entre el sistema de possessió institucional i el sistema de castes, i analitza més particularment la construcció de l'organització social i de la cosmologia en una regió de I'Himalàia indi. En aquest article parlarem de la possessió i de les divinitats locals, particularment de la relació entre el món social i el món còsmic des d'aquesta perspectiva.

Les religions més presents en la població índia són I'Hinduisme (80,5\%), I'Islam $(13,4 \%)$, el Cristianisme (2,3\%), el Sikhisme (1,9\%), el Budisme (0,8\%) i el Jainisme $(0,4 \%)^{3}$. Es pot dir de l'Hinduisme que és una religió íntima, en el sentit en què es practica essencialment dins de la Ilar, en I'esfera familiar. Cada matí, la família honora diversos déus - de vegades amb una preferència per un déu "de família" - banyen les estàtues, les perfumen, els alimenten amb llet i mel, els regalen flors fresques, cants, oracions. Cada àpat està ofert als déus, i dipositen, abans de menjar, una part de l'aliment a prop del foc, considerant que el que la família menja tot seguit són de fet les restes de l'àpat diví. Cadascú escull la seva manera de practicar la religió, d'oferir sacrificis, de practicar expiacions, i molts escullen per exemple un dejuni a la setmana, però és únicament per elecció pròpia. Els esdeveniments del cicle de la vida (naixement, primer tall de cabell, aniversaris d'un fill únic, per exemple) són celebrats de manera religiosa a casa, amb un purohit (astròleg), en presència de la familia nuclear. Algunes festes religioses col-lectives marquen tanmateix l'any, però fins i tot la puja, que és la cerimònia d'ofrenes als déus en el temple, no pot ser considerada com una celebració col-lectiva ja que durant aquest ritual els devots passen cadascun al seu torn a donar al pujari (oficiant que realitza la puja) encens, flors i fruits, ofrenes que I'oficiant en qüestió remet als déus, recitant formules establertes.

\footnotetext{
${ }^{3}$ Census of India 2001:

http://www.censusindia.gov.in/Census_Data_2001/India_at_glance/religion.aspx
} 


\section{perifèria}

Número 9, Diciembre 2008

www.periferia.name

L'Hinduisme intenta conciliar un cert monoteisme (considerant Baghwan o Ishwar com el Senyor font de tota creació) amb una llarga sèrie de déus igual d'efímers que I'home o els animals, i que desapareixeran amb ells al final del cicle ${ }^{4}$, per renéixer sota una altra forma quan Baghwan recrearà de nou el món. Els més importants d'aquests déus són Vişnu (també sota la forma de Rama i Krishna), Śiva, Brahma, Ganeş, la Deesa (sota la forma de Kali o Laxmi, entre d'altres), que es troben sobre tot el territori indi.

Al costat d'aquestes figures omnipresents, no és escàs trobar, segons les regions, altres divinitats que varien d'un estat a l'altre, d'una vall a l'altra o fins i tot d'un poble a I'altre. Les designarem, doncs, sota la denominació de "divinitats locals" o devta, segons el terme utilitzat en la regió estudiada. A la vall de Kullu (Himachal Pradesh), aquestes divinitats locals poden prendre diverses formes: el Mantra (formula màgica), el Pinda (petita pedra o boleta de fang o de fem de vaca), el Yantra (dibuix geomètric), la Murti (estàtua), com les divinitats generals del panteó hindú, però poden també, a diferència d'aquestes últimes, prendre forma en un Rath (palanquí portat per dos homes) o en un gur, és a dir un posseït institucional.

Els materials que he analitzat han estat recollits durant un treball de camp de tres mesos realitzat a la tardor del 2006 en un conjunt de vint-i-tres pobles ${ }^{5}$ situats en el centre de la vall de Kullu, a Himachal Pradesh, un estat del nord de I'Índia, entre el Pakistan, el Caixmir i el Tíbet. La regió estudiada esta situada entre 1750 i 2500 metres d'altitud ${ }^{6}$ i és part de la cadena de I'Himalàia. L'economia esta basada en I'agricultura (en terrasses), la ramaderia de cabres i la recollida de pomes.

\footnotetext{
${ }^{4}$ Un cicle té une durada de 4.320.000 anys, i està dividit en quatre èpoques. La primera és una "Edat d'Or", regne de la puresa, i l'última (de la qual la nostra època actual n'és part) és l'era de la degradació, de la maldat i de la barreja. Al final d'un cicle, tot desapareix, fins i tot els déus, i tot torna a néixer sota una altra forma, gràcies a la voluntat de Baghwan, i els universos es succeeixen així sense parar (Tardan-Masquelier 1999: 90). Aquesta concepció proposa doncs una manera hàbil de conciliar la temporalitat i l'infinit, el monoteisme i el politeisme.

${ }^{5}$ Són els pobles al voltant de Jibhi, entre Banjar i Jalori Pass, a 60 km de Kullu.

${ }^{6}$ Google Earth, 1 de novembre 2008
} 


\section{perifèria}

Número 9, Diciembre 2008

www.periferia.name

Com a la resta de I'Índia, la societat esta dividida en castes, és a dir grups hereditaris i endògams (Dumont 1966), que es consideren interdependents, encara que avui en dia aquesta interdependència és més simbòlica o ritual que material $i$ econòmica. Els diferents grups s'ordenen en una jerarquia relativa i no-linear, a partir de criteris com compartir l'aigua o la pipa per exemple. A part del fet que els Braman es posicionen sempre a dalt de tot, aquesta jerarquia és difícil de captar car les ocasions de posar-la a prova són de vegades escasses. Així, és possible que una persona de la casta dels carnissers no hagi tingut mai I'ocasió de compartir un àpat o una conversa amb una persona de la casta dels escombriaires, i no pot doncs afirmar si poden compartir la cigarreta i qui dels dos pot oferir aigua a l'altra, cosa que ajudaria a situar aquestes dues castes en la jerarquia local. Car les castes, que són milers a la Índia, varien d'una regió a l'altra, d'una vall a l'altra. El sistema és el mateix, però els seus components són diferents. En el conjunt dels vint-i-tres pobles que hem estudiat censem la casta dels Braman (casta de "sacerdots"), la dels Rajput (que es diuen descendents de famílies reials, i que són els més nombrosos a la regió), els Kumar (orfebres-esculptors), els Tarkan (fusters), els Dagi (tocadors de tambors), els Lohar (ferrers), els Camar (adobers) i els Doomnay (fabricants de cistells de palla). Els Braman són, com a la resta de l'Índia, dalt de tot de la jerarquia. Els Tarkan, Dagi, Lohar, Camar i Doomnay formen un conjunt de castes baixes i intocables, que s'agrupen sota el nom de Harijan ${ }^{7}$, i entre els quals la jerarquia no és clara, excepte per als Camar que es troben a la posició més baixa. Entre els Braman i els Harijan, es situen els Rajput i els Kumar, dels quals no es pot dir amb certesa que un estigui més amunt que l'altre en l'escala de I'estatus. Anita, una vídua de 55 anys, explica:

Són diferents, però iguals. Com els elefants i els lleons. L'elefant és fort, és gran, és intel·ligent, és un bon animal. El lleó també és fort, és ràpid, és astut, un bon animal. Són igual de bons. Però són diferents. És el mateix pels Rajput $i$ els Kumar: són diferents, tenen la sang diferent, però no n'hi ha cap que sigui millor que l'altre.

\footnotetext{
7 Harijan ("nens de déu") és el nom escollit per Gandhi per designer els intocables i les castes més baixes (Tardan-Masquelier 1999: 216).
} 


\section{perifèria}

Número 9, Diciembre 2008

www.periferia.name

És tanmateix aquesta mateixa Anita que, alguns dies més tard, em digué:

El gur de Śeş $\mathrm{Nag}^{8}$ diu que és Rajput. Però no és veritat. És d'una casta més baixa: és Kumar.

Quan la seva jove li replicà que s'equivocava i que el gur era de casta Rajput, continuà:

Bé, ara sí que és Rajput, però la seva sang encara té gotes de Kumar. A la seva família, va haver-hi un matrimoni Rajput-Kumar; per tant ell no és totalment Rajput, és encara una mica Kumar, i per més que els seus descendents es continuïn casant amb Rajput, no podran mai esborrar-ho.

Aquestes diferents castes estan repartides geogràficament. Si en altres regions de I'Índia un mateix poble comprèn diverses castes amb una zona per als Braman, una zona per als intocables, i així successivament, a la regió que hem estudiat no és exactament així: les diferents castes estan més o menys dividides en pobles diferents, i dels vint-i-tres pobles que formen la zona analitzada, trobem les castes baixes en dos pobles i mig, mentre que els Rajput els trobem en vint pobles i mig. Els escassos Braman de la regió viuen barrejats amb els Rajput i els Kumar viuen en pobles fora de la zona estudiada.

Els habitants de la regió distingeixen dos grups entre les castes: els Baharke ("de fora") i els Andarke ("de dins"). Els Baharke són les castes que no tenen dret a entrar al temple, a diferència dels Andarke que sí tenen el dret d'entrar-hi. En els pobles estudiats, els Baharke corresponen a totes les castes Harijan, i els Andarke estan composats dels Braman, Rajput i Kumar. Que tinguin la prohibició d'entrar al temple no significa de cap manera que els Baharke no poden participar als cultes religiosos. En primer $\mathrm{Iloc}$, aquestes castes baixes es reserven divinitats locals que resideixen en els seus pobles. Fins aquí, podríem pensar que existeixen dos cultes religiosos separats, un per les castes altes (Andarke) i un per les castes baixes (Baharke), impressió que els habitants fomenten, presentant la majoria dels aspectes del culte com a desdoblats ${ }^{9}$. Però no és el cas, car les castes baixes estan,

\footnotetext{
${ }^{8}$ Śeş Nag és la divinitat local del poble Jibhi i regna sobre vint-i-tres pobles.

${ }^{9}$ Els pobletans expliquen per exemple que hi ha un gur per les castes altes i un gur per les castes baixes (i això que hi ha diversos déus i diversos gur); les castes altes declaren no saber res dels gur de les
} 


\section{perifèria}

Número 9, Diciembre 2008

www.periferia.name

a més, fortament implicades en el culte de les divinitats locals que regnen sobre tots (per exemple en el culte del déu Śeş Nag, un déu cobra que regna sobre el conjunt dels vint-i-tres pobles estudiats). Més encara: estan al servei de divinitats de pobles exclusivament Rajput, com Lethora, la divinitat de Bhalegaon, un poble composat de famílies Rajput únicament. Són sobretot els Dagi (casta baixa de tocadors de tambors) aquells que hom requereix més sovint, ja que són els únics que poden ( $\mathrm{i}$ han de) tocar el tambor quan s'organitza una festa en honor d'una divinitat o bé quan aquesta es desplaça. És una de les ocasions en què la interdependència de les castes pren tot el seu sentit: són interdependents al voltant del sacrifici i del ritual, i és el que explica el fet que hi ha per exemple en algunes regions de l'Índia castes d'agricultors en un país on la majoria dels individus es dedica a l'agricultura (Baechler 1988: 53-57; Deliège 2006: 35 i 108; Dumont 1966).

\section{La possessió ritual}

"Possessió" és un terme que cobreix una multitud de fenòmens diversos, però que tenen tots un punt en comú: alguna cosa domina algú, que perd el control de la situació i no pot respondre dels seus actes o paraules. Tota definició més precisa restringiria obligatòriament, al nostre parer, la infinitat de possibilitats d'aquest tipus de comunicació amb l'Altre-món.

Aquesta "alguna cosa" pot ser un déu, un esperit, un fantasma, una força. Pot moure's sola, actuar per iniciativa pròpia, o al contrari estar enviada per algú: un altre déu, una bruixa, un veí, un parent.

Aquesta "alguna cosa" pot entrar en el cos de la persona posseïda, per l'anus, la boca, les orelles, els ulls, el cim del crani, els cabells o el nas; pot desplaçar el Jo de la víctima i instal-lar-se en el seu lloc, o al contrari conviure-hi simplement ${ }^{10}$; però pot també no entrar en el cos de la víctima, i "posseir" la víctima des de

castes baixes, i declaren fins i tot no saber-ne ni tan sols el nom, i això que tots els pobletans, sigui quina sigui la seva casta, estan molt més lligats, també a nivell religiós, que no el que volen demostrar.

${ }^{10}$ Vegeu la discussió entre Kakar i Mayaram (Mayaram, 1999: 104) 


\section{perifèria}

Número 9, Diciembre 2008

www.periferia.name

I'exterior, controlant les seves forces i paraules; pot igualment exercir una influència general, que esdevindrà un lligam impedint la persona d'actuar, de pensar i de parlar per ella-mateixa, o fins i tot fent-la emmalaltir. L'acció d'aquesta "cosa" s'estén de vegades sobre l'individu en un sentit ampli, és a dir sobre tot el que compon la seva persona: la seva família pot patir-ne, la seva casa ser incendiada, la seva feina perduda, els seus estudis fracassats. És així com les conseqüències de la possessió són de vegades dissociades: una persona esta posseïda i és el seu fill que esta malalt (Krengel 1999: 270).

Acabem de pintar un quadre bastant negatiu de la possessió, però no sempre està considerada així: de vegades, desprès d'haver sofert la possessió, l'individu aconsegueix controlar-la, no deixar-se assaltar en qualsevol moment, canalitzar-la en un marc espacio-temporal, un ritual. És aquí on trobem els posseïts institucionals, que estan al servei d'un déu i que els serveixen de receptacles.

Aquesta definició difereix en diversos punts de la donada, per exemple, per J-P Olivier de Sardan en el Dictionnaire de l'ethnologie et de l'anthropologie, que cito:

Le principe de base de la possession est le même partout: dieux, esprits ou génies (peu importe comment les ethnologues les nomment) qui constituent souvent une sorte de panthéon anthropomorphique plus ou moins structuré, "investissent" le corps d'un être humain le temps d'une transe, en général lors d'une cérémonie organisée à cet effet. Le "possédé", le "médium" (souvent considéré dans sa propre société comme le "cheval" du dieu qui le "chevauche", ou comme son "époux"), adopte alors le comportement qui est censé être celui du dieu en question. [...]; l'état de transe qui accompagne la possession, "état altéré de conscience", comme disent les Anglo-Saxons, est en fait socialement construit. Tout le temps que dure la possession, le sujet n'est plus lui-même, il "est" ce dieu, et s'il arrive que pendant la transe il parle, c'est le dieu qui parle par sa bouche (il admoneste, exige, révèle, prophétise, selon des codes sociaux assez définis...). La fin de la transe, c'est le départ du dieu: le sujet, prostré, redevient lui-même et ne se souvient plus de rien (Olivier de Sardan 2002: 595).

Tal com és descrita per aquest autor, la possessió deixa un lloc únic al cos del posseït. Ara bé, i encara que en sigui un aspecte important, acabem de veure que justament la possessió no es detén al cos de l'individu posseït sinó que s'estén fins a la seva família, la seva casa, el seu entorn més proper. I és que a l'Índia, a més, s'ha d'entendre que un individu no es limita a un cos, amb eventualment una

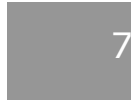




\section{perifèria}

Número 9, Diciembre 2008

www.periferia.name

ànima. La seva terra, el seu poble, són part de l'individu (Deliège 2006: 91). Són les seves arrels en el sentit literal. Quan considerem la possessió d'una persona, no podem doncs limitar-nos al seu embolcall físic: hem de tenir en compte tots els seus components, que sobrepassen amplament el cos.

El segon punt d'aquesta definició que ha de ser matisat és el del trànsit: efectivament, no hi ha d'haver sempre trànsit perquè hi hagi possessió ( $i$ a la inversa, la possessió no és necessària per assistir a demostracions de trànsit) (Tarabout 1999: 12; Lewis 1989: 25). En els pobles que he estudiat, per exemple, els posseïts no manifestaven cap tremolor, cap canvi significatiu de comportament a partir del moment en què havien incorporat la divinitat. Desfeien els seus llargs cabells i parlaven simplement, i amb les seves paraules s'entenia que era la divinitat qui s'expressava.

Aquestes possessions rituals s'inserten en un marc espacio-temporal, és a dir que no tenen lloc de forma improvisada: el posseït institucional (que anomenarem a partir d'ara gur, segons el vocable local) es prepara, així com el pujari (sacerdot) i els devots. És un marc temporal, car el gur rep la divinitat en ell en moments concrets: durant les consultes el matí, durant els exorcismes, i en certs moments dels rituals celebrats durant les festes. Fora d'aquests moments, el gur no és la divinitat, només és un pobletà com els altres. I és un marc espacial, perquè la possessió no pot arribar en qualsevol lloc: la possessió del matí, quan els devots venen a consultar la divinitat, només es pot desenvolupar davant del temple del poble. No a dins del temple, on es troba l'estàtua del déu, ja que hi hauria llavors un "excés de divinitat", però just davant, és a dir a proximitat d'una forma fixa del déu. Si s'espera una possessió a fora del recinte del temple, per una festa per exemple, el gur incorporara la divinitat davant del palanquí d'aquesta última (anomenat rath, és una estructura composta d'un munt de teixits, collars, flors, ombrel-la de plata i cares de metall, portada per dos homes gràcies a dues fustes flexibles llargues i primes, cosa que provoca moviments del palanquí, tot donant-li vida). Els exorcismes, que es desenvolupen generalment a casa de la víctima o a la seva casa natal, requereixen discreció (per no atreure els altres esperits), cosa que és impossible amb el palanquí, ja que aquest sempre ha d'estar acompanyat de 


\section{perifèria}

Número 9, Diciembre 2008

www.periferia.name

tambors. La divinitat estarà doncs representada per un encenser i una petita campana, i és davant d'aquests dos objectes que el gur podra incorporar la divinitat. Així, tot i que la divinitat pot prendre cos en qualsevol punt del territori, calen tanmateix algunes condicions espacials, com la proximitat d'una de les seves formes: estàtua, palanquí, o encenser i campana.

Com Daniela Berti (Berti 1999), podem afirmar que la possessió institucional és un marc fix (fet de fórmules i preparacions rituals) dins del qual tot evoluciona: la vida social de cada devot i del poble en general és analitzada, interpretada. Aquesta anàlisi divina és negociada pels habitants del poble, que contesten, es queixen, s'enfaden, amenacen la divinitat, tot romanent sempre respectuosos amb ella. La relació dels devots amb la divinitat és doncs de negociació més que de submissió. En efecte, tota la ciència del gur resideix en la seva habilitat a proposar interpretacions al problema del devot (problema que pot ser una malaltia, bestiar malalt o robat, una casa incendiada, una depressió, un fracàs escolar, una sospita de possessió per un esperit, o encara, per exemple, un excès o una falta de pluja) i a redirigir constantment les seves interpretacions segons la manera en què aquestes estan acollides pel devot en qüestió. Aquest subtil tempteig de propostes segueix la idea que el devot s'ha fet, abans de consultar la divinitat, de la causa del seu problema, encara que les explicacions són presentades sempre com I'omniciència del déu, que ho sap tot i ho veu tot. En alguns casos en canvi, la divinitat s'oposarà fermament a les hipòtesis del devot per defensar les seves. Quant al gur, està considerat com un simple receptacle, que ha de ser pur (ha de respectar algunes regles, com no beure alcohol, no fumar, no portar objectes de cuir, banyar-se abans de cada consulta i respectar al màxim les regles de castes), però que no posseeix en sí cap qualitat particular, a part de la d'haver estat escollit pel déu. Aquesta concepció d'un home-objecte, receptacle, comporta la seva desresponsabilització: tot el que diu i fa durant la possessió és obra de la divinitat, i 


\section{perifèria}

Número 9, Diciembre 2008

www.periferia.name

el gur no n'és de cap manera responsable. A més, hom considera que no té cap record de tot el que ha passat durant la possessió ${ }^{11}$.

Oficialment, el déu escull la seva "boca" entre tota la població sobre la qual regna, castes baixes incloses; en la realitat, és sovint dins de la mateixa casta, i fins i tot dins de la mateixa família, que el gur esta escollit. A Jibhi per exemple, quan el vell gur és mort, els homes de la seva família s'asseuen en línia davant del temple, i esperen, fins que I'un d'ells mostra signes d'elecció divina. De fet, aquest elegit diví ja ha estat escollit amb antelació, de manera més o menys amagada, pel sacerdot (pujari) i l'antic gur, que l'instrueix en secret. El signe de l'elecció divina és un trànsit sobtat, seguit per una carrera desenfrenada de tres dies a través dels boscos, pujant la muntanya cap a un llac sagrat. A la seva tornada, el pujari (sacerdot) condueix un ritual de mort i de renaixement simbòlics a continuació del qual l'elegit esdevé gur per tota la vida, i això encara que un dia pugui ser rebutjat per la comunitat ${ }^{12}$.

Aquesta funció de "boca de la divinitat" no confereix al gur cap estatus particular, i ha de respectar al màxim les regles de castes (no compartir aigua, àpats o contactes físics amb castes inferiors, no entrar dins de cases de castes superiors, casar-se dins de la seva casta). De fet ha de ser més estricte amb aquestes regles que els altres pobletans, i si podem constatar algunes infraccions de regles de castes entre els altres habitants de la vall (com alguns contactes físics en el moment de passar objectes de mà en mà, o el compartir una cigarreta), s'espera del gur que sigui gairebé un model d'ortodòxia: els objectes donats o rebuts per altres castes es passen amb l'ajuda d'un mocador per exemple, per evitar tot

\footnotetext{
${ }^{11}$ El que Mastromattei designa per "amnèsia ritual" (Mastromattei 1988: 83, in Berti 2001: 114) i que Hamayon anomena "prohibició cultural" (Hamayon 1995: 25 in Berti 2001: 114)

12 El gur de Ghiyagi, casat amb una dona de la seva casta i del seu poble, anava regularment a Delhi, trencant d'aquesta manera la regla segons la qual un gur no pot allunyar-se de la seva regió. A més, es relacionà amb una altra dona, a més d'una casta més baixa que la seva. Quan la portà a Ghiyagi per viure junts, els pobletans el rebutjaren i, sense preguntar l'opinió del déu, escolliren un altre gur, de fet el nebot de l'antic gur rebutjat. Aquesta elecció és humana i no divina, i els pobletans no poden per tant impedir l'antic gur d'anar ocasionalment al temple per obrir una sessió de consulta quan els escassos pobletans que encara creuen en ell li demanen.
} 


\section{perifèria}

Número 9, Diciembre 2008

www.periferia.name

contacte, fins i tot indirecte. Quan el gur pren aquestes regles a la lleugera, les crítiques són dures i les amenaces fortes ${ }^{13}$.

El recodatori de la importància de la separació de castes és un punt recurrent del seu discurs durant la possessió per la divinitat, i molts mals actuals s'expliquen per la barreja en general, sobretot la barreja de castes.

\section{Les divinitats encarnades}

Les divinitats locals, anomenades devta, tenen com a particularitat l'estar lligades a un territori concret, al contrari de les altres divinitats del panteó hindú. Si aquestes últimes tenen una mitologia ben dibuixada, amb una representació fàcilment identificable, els devta de la vall de Kullu no es diferencien gaire entre ells a nivell iconogràfic, i les seves histories no estan considerades com a importants, ja que en general no són conegudes pels pobletans ni de vegades ni tan sols pels mateixos gur i pujari (sacerdot) mateixos. El que compta, és el territori sobre el qual cadascú regna. Aquests territoris estan perfectament dibuixats i coneguts per tots els habitants de la zona; van des d'una meitat de poble fins a un centenar de pobles, i s'engloben els uns en els altres. És així com el devta Śringa Rişi regna sobre un centenar de pobles, repartits en diverses zones, cadascuna de les quals té un altre déu, com per exemple Śeş Nag, que regna sobre vint-i-tres pobles. Diversos d'aquests pobles, sota la jurisdicció de Śeş Nag, tenen a més un altre devta, com Djal que regna sobre el poble Kandi, un poble Harijan; o Lethora, que regna sobre el poble de casta Rajput de Bhalegaon. Segons el context, un devta estarà considerat com a sobirà absolut o com a simple vassall, "Primer Ministre", "petit ministre" o "soldat", com els designen els pobletans. Djal, sobirà absolut sobre el seu poble Harijan (Kandi), només és un déu vassall de Śeş Nag si ens situem a escala dels vint-i-tres pobles. Śeş Nag, al seu torn, omniscient i omnipotent sobre el seu petit territori, esdevé vassall del déu Śringa Rişi si mirem el conjunt dels cent pobles.

\footnotetext{
${ }^{13}$ El nou gur de Ghiyagi, és a dir el nebot de I'antic gur rebutjat, és al seu torn fortament criticat per els pobletans que no aprecien gaire la lleugeresa de les seves paraules, la seva manca d'educació en públic i la seva atracció per les joves estrangeres.
} 


\section{perifèria}

Número 9, Diciembre 2008

www.periferia.name

Aquestes divinitats locals s'engloben doncs les unes en les altres des d'un punt de vista territorial, sense que això fixi cap jerarquia divina: el "petit" deú Pancbdir, que regna sobre la meitat Harijan del poble de Kuthathi, és considerat més petit que Śringa Rişi, ja que només regna sobre mig poble mentre que I'altre regna sobre un centenar de pobles; però és també una forma de Vişnu que és, amb Śiva, el déu més important del panteó hindú.

Vidal, fa alguns anys, ja havia insistit sobre la importància de l'aspecte territorial en la definició de les divinitats locals, cosa que hem de tenir present si no volem esbiaixar la investigació creient que, perquè els pobletans no en coneixen ni la historia ni la iconografia, aquestes divinitats són menys importants que les "grans" divinitats hindús (Vidal 1988: 37-39).

Aquesta territorialitat defineix no només el caràcter de cada devta, sinó també les relacions entre ells, com subratlla Berti:

[...] le critère fondamental qui est à la base des liens rituels entre les divinités de village, et qui implique toutes les divinités de la région, est celui qui fait intervenir des relations territoriales (Berti 2001: 145).

Així lligats a un territori i a un grup de pobletans, els devta estan involucrats dins d'una xarxa de relacions, cosa que implica algunes obligacions -anar a les festes en honor a altres devta, participar als rituals en els quals altres devta del mateix territori estan implicats- però que té l'avantatge de poder ser utilitzada per alguns propòsits pels gur, com ens mostra Berti: en l'exemple que ens dóna, dos pobles estan barrallats, en plena època de sequera. El gur consultat (posseït) estableix un vincle directe de causa - efecte entre la barralla (interpretada com una separació dels dos devta per uns homes) i la falta de pluja. Tots els pobles que pateixen d'aquesta sequera pressionen llavors els dos pobles en conflicte cap a una reconciliació, perquè els déus, contents de trobar-se de nou, deixin caure la pluja. El gur ha aconseguit, doncs, utilitzar la xarxa de pobles per resoldre una barralla en el seu territori (Berti 2001: 257-279).

El fet que les divinitats locals no es distingeixin practicament entre elles permet una adaptació constant de les seves competències en funció dels èxits dels gur. Al llarg de l'any, un pot haver tingut més sort per fer caure la pluja, l'altre per curar tal 


\section{perifèria}

Número 9, Diciembre 2008

www.periferia.name

malaltia, i així successivament. Aquests èxits seran interpretats com a competències de les divinitats, que aquestes últimes hauran guanyat jugant als daus entre elles, quan es retiren a la muntanya a I'hivern.

Aquesta absència de fronteres fixes entre els diferents devta és vàlida igualment entre ells i altres entitats: hem esmentat més amunt que el "petit" devta Djal, del poble Kandi (de casta Harijan), és de fet Vişnu; passa el mateix amb Pancbdir, el devta dels Harijan que ocupen la meitat del poble Kuthathi. És doncs impossible separar els déus en dues categories, d'un costat els "grans" déus hindús i d'un altre els "petits" déus locals ja que, encara que en la forma difereixen, són de fet la mateixa essència. Berti ens dona un exemple que il.lustra perfectament la complexitat i l'ambigüitat de la relació entre aquests dos tipus de déus: després d'una mala collita de pomes, els productors i les divinitats locals (per la boca dels seus gur) decideixen organitzar un ritual en I'honor de les "grans" divinitats del panteó hindú. L'autora subratlla la multiplicitat dels papers que agafen les divinitats locals, que es distingeixen dels altres déus i al mateix temps es confonen amb ells: d'un costat es queden molt "locals", ja que són elles les que organitzen, al mateix nivell que els productors de pomes, el ritual per honorar els altres déus. D'un altre costat, es posicionen al mateix nivell que aquests últims, ja que estan dibuixades en els Yantra, formes geomètriques dibuixades a terra que representen els déus generals del panteó hindú. A més, un cop tot esta acabat, són elles les que jutgen (per la boca dels gur) si el ritual ha estat correctament acomplert i estan doncs reconegudes com a "divinitats supremes" (Berti 2001: 135-138). Berti en conclou que els ritus de possessió, a la vall de Kullu, engloben els ritus brahmanics, però també que tota demarcació neta entre panteó bramànic i panteó local -més sovint distingits, en certs contextos, a nivell del discurs- és impossible (Berti 2001: 142).

Sembla doncs endebades de voler buscar una diferència ontològica entre aquests dos grups de déus. En canvi, Vidal proposa una interpretació interessant, que es basa no sobre una qüestió d'essència, sinó altra vegada sobre una qüestió de territorialitat: els déus locals es demarcarien justament perquè han escollit quedarse amb els homes (Vidal 1988: 257), establir-se amb ells, viure, comunicar i celebrar les festes amb ells. Seria doncs aquesta elecció de vida social, respecte a 


\section{perifèria}

Número 9, Diciembre 2008

www.periferia.name

la Renúncia ascètica dels déus generals del panteó hindú, el que distingiria els devta ${ }^{14}$.

A la dificultat -o a la manca de sentit- de separar ontològicament els déus en dues categories s'afegeix un altre tipus d'entitats amb els quals es confonen els devta: són els bhut. Aquests sers sobrenaturals, entre esperits i fantasmes, són en general persones mortes abans d'hora o en circumstàncies dramàtiques: dones mortes parint, pobletans ofegats, suïcidats, assassinats o encara caiguts a la muntanya. Moguts per la venjança i la gelosia, o enviats per un humà gelós, ataquen els vius, aprofitant l'ocasió en que algú es troba en un espai-temps de debilitat o de límit, com les dones embarassades o parint, els pobletans que travessen els ponts, els que passegen al crepuscle, a prop del camps de cremació ${ }^{15}$. Provoquen mals de cap, marejos, esvaïments, canvis d'humor, un comportament agressiu, depressions, impotència, esterilitat, esgotament sexual, fracàs escolar, malalties, pèrdua del bestiar, incendis, avortaments i accidents. És sobretot la combinació de diversos problemes ${ }^{16}$ que és preocupant, i que empenyarà la família de la víctima ${ }^{17}$ a diagnosticar la possessió ${ }^{18}$. Si la divinitat local confirma aquest diagnòstic, s'haurà de realitzar un exorcisme, que es fara de nit, a casa (o a la casa natal) de la víctima.

En els discursos, devta i bhut es distingeixen, principalment per la malevolència dels bhut. En la pràctica, aquesta diferència ontològica no es retroba gaire: en primer lloc els bhut poden ser favorables a alguns humans i fer-los favors, per poc

\footnotetext{
${ }^{14}$ Diuen que els déus del panteó hindú, com uns ascetes, s'han retirat sobre el mont Kailāś.

15 Lògicament, el llindar de la porta de la casa, límit entre l'interior i l'exterior, hauria de representar també un perill, però non'és el cas: és sobre el llindar de la porta on es mantenen moltes xerrades amistoses inter-castes, cosa que els permet compartir un te i galetes. S'ha de saber que un individu no té dret a entrar a casa d'una persona de casta superior, i no pot acceptar aliment d'una casta inferior. Quan dos amics de castes diferents es troben, és doncs molt còmode per ells seure sobre el llindar de la porta de l'amic de casta superior, sense que I'amic de casta inferior entri a dins, i poden d'aquesta manera compartir el te i les galetes que prepara l'amic de casta superior.

${ }^{16}$ El que Favret-Saada anomena "Infortuni". (Favret-Saada 1977)

${ }^{17}$ La víctima no es diagnostica mai la possessió ella-mateixa.

18 Tanmateix aquests símptomes també poden ser interpretas (per la divinitat a través del seu gur) com un mal destí, una configuració astral desfavorable, un càstig diví, una maledicció, l'acció d'una bruixa o la pèrdua de l'ànima. (Berti 2001: 178-193)
} 


\section{perifèria}

Número 9, Diciembre 2008

www.periferia.name

que els venerin; poden igualment estar al servei d'una divinitat ${ }^{19} \mathrm{i}$ acomplir per a ella les tasques més sangonoses, i rebre els sacrificis d'animals en el cas de divinitats vegetarianes; es diu també d'alguns devta que són antics bhut assenyats, sobretot si han trobat algun Iloc fix on puguin ser venerats, com apunta Dumont per al Sud de l'Índia:

Un démon ou un esprit devient un dieu lorsqu'il devient l'objet d'un culte régulier (Dumont 1957, In Berti 2001: 121).

D'altra banda, els devta tenen de vegades mal caràcter, o són capriciosos, i no es priven de castigar un pobletà o el poble sencer per alguna falta; poden esdevenir violents si no se'ls honora prou al seu gust. La diferència entre devta i bhut seria més aviat de I'ordre de la residència/itinerància: un bhut podria esdevenir devta a partir del moment en què troba un lloc on pugui ser honorat, i un devta podria teòricament esdevenir malèvol, apropant-se doncs dels bhut, des del moment en què és negligit o oblidat ${ }^{20}$. Berti mostra que alguns devta es caracteritzen

(...) non seulement par l'ambivalence de leurs aspects positifs et négatifs, mais aussi par leur capacité à se transformer ontologiquement de devta à bhūt, et vice-versa (Berti 2001: 158).

La plasticitat de les divinitats locals depen igualment del locutor: una mateixa divinitat estarà considerada carnívora pels devots carnívors, però vegetariana pels devots vegetarians; la casta del locutor pot igualment interferir a aquest nivell, ens diu Berti, i un devta de castes baixes pot estar considerat per les castes altes com un bhut (Berti 2001: 156). Yasushi Uchiyamada apunta la mateixa polivalència per a Kerala (Índia del Sud):

[Moreover], the nature of possessing beings is perceived differently by differently positioned subjects. For instance, the lineage deities of Untouchables are benevolent deities from the point of view of the lineage members. Nevertheless, high-caste neighbours usually see these deities as malevolent demons (Uchiyamada 1999: 291).

\footnotetext{
${ }^{19}$ Com a vahan: veure més avall

${ }^{20}$ Daniela Berti planteja que els bhut no tenen residència fixa, a diferència dels devta, i que segurament el fet que un bhut sigui honorat en un lloc precís fa que se I'anomeni "devta". (Berti 2001: 159)
} 


\section{perifèria}

Número 9, Diciembre 2008

www.periferia.name

Existeix un altre tipus d'entitats amb les quals es confonen els devta, i que participen de la seva complexitat i ambigüitat: són els vahan, és a dir els guardes (no-humans) de les divinitats locals. Considerats com a violents i sanguinaris, compleixen les tasques obscures de la divinitat a la qual estan lligats, i es beneficien dels sacrificis sangonosos quan aquesta, vegetariana, no els pot acceptar. Les divinitats i els seus guardes estan associats, i aquesta parella coincidiria no només amb l'eix pur/impur ${ }^{21}$, sinó que sobretot acoblaria la complementarietat que uneix les castes altes i les castes baixes (Vidal 1988: 256). Aquesta complementarietat entre les diferents castes no és l'única característica de la seva relació que està reflectida en la cosmologia: la subordinació és igualment un aspecte que es troba en la relació entre els devta i els bhut. Es tracta de subordinació més que de victòria, ja que, encara que els devta poden neutralitzar, sotmetre i controlar les entitats malèvoles, no poden, en canvi, eliminar-les definitivament (Vidal 1988: 262).

\section{Conclusió}

En el món hindú, l'ordre còsmic i l'ordre social s'influencien mútuament i estretament: no només els déus, sinó també els planetes són per exemple un factor determinant en la vida i el destí de cada individu, d'aquí la importància dels astròlegs (dits purohit) a cada moment-clau de la vida. A l'inrevés, I'ordre còsmic depèn dels gestos i comportaments dels individus, d'aquí la importància de la perfecció dels rituals, de la puresa dels que I'acompleixen, i de I'Ordre en general, entre d'altres i sobretot la separació de castes. Podríem imaginar un cert paral-lelisme entre aquests dos móns, però no és així: en primer lloc els déus de castes baixes no són inferiors als déus de les castes altes. Djal, el devta de Kandi, un poble Harijan, no és inferior a Lethora per exemple, que és el devta del poble Bhalegaon, un poble de casta Rajput. La jerarquia dels homes no determina, doncs, la jerarquia dels déus. No dibuixa, tampoc, cultes separats: al principi del meu treball de camp, creia que el culte religiós estava separat en dos grups, un per als

\footnotetext{
${ }^{21}$ Una noció, entre altres, fonamental a la comprehensió del sistema de castes. (Vegeu Deliège 2006)
} 


\section{perifèria}

Número 9, Diciembre 2008

www.periferia.name

Andarke ("de dins", és a dir les castes que poden entrar al temple) i un altre per als Baharke ("de fora", és a dir les castes que no poden entrar al temple). Aquesta impressió venia entre d'altres dels comentaris dels pobletans, que insistien sempre sobre la separació entre els Andarke i els Baharke, o que afirmaven que hi havia un gur per a les castes altes i un gur per a les castes baixes (cosa que no era exacta, ja que com hem vist hi ha un gur Rajput per tots els habitants del conjunt dels vinti-tres pobles i diversos gur Harijan, un per cada poble Harijan). El repartiment geogràfic de les castes i el fet que els Harijan consulten el gur del seu poble (que és doncs Harijan), mentre que els Rajput consulten el gur Rajput de Śeş Nag 22 recolzaven aquesta hipòtesi de dos cultes separats. Això no obstant, l'anàlisi de les dades recollides durant el treball de camp ha pogut mostrar que no és així, i que les interaccions entre castes es donen també a nivell ritual, aplegant aquestes diferents castes en un sol conjunt religiós: en primer lloc, els tamborers, indispensables al culte, són tots, obligatòriament, de casta baixa. Han de ser presents a tots els desplaçaments de la divinitat, i es considera que tenen un vincle afectiu molt fort amb ella. Aquest paper no és sorprenent, si recordem que el sistema de castes és abans de tot religiós, i que les diferents funcions que s'atribueixen a cada casta són de fet funcions dins del ritu. És doncs normal que uns Harijan estiguin integrats al culte d'una divinitat que regna sobre tots, com Śeş Nag per exemple. Però aquests tamboriners han de ser també presents als cultes de divinitats que regnen únicament sobre pobles Rajput, com Lethora (del poble Bhalegaon) o Vişnu del poble de Sar (de casta Rajput igualment), que són divinitats que en principi semblaven no tenir cap vincle amb els tamborers. A més, hem pogut veure que els devta Harijan estan convidats a les festes i rituals organitzats per pobletans de casta Rajput, com la festa privada d'agraïment organitzada per una família Rajput en honor a Śeş Nag i a Śringa Rişi, on tres petites divinitats estaven igualment invitades, entre altres Djal, el déu del poble Kandi (de casta Harijan). En el cas d'aquest ritual privat, que durà tres dies i aplegà unes dues mil persones, els Harijan no estaven presents únicament com a convidats: en efecte, és un dels

\footnotetext{
${ }^{22}$ Només pot haver-hi un gur Rajput per zona.
} 


\section{perifèria}

Número 9, Diciembre 2008

www.periferia.name

seus, el gur Harijan del devta Pancbdir (devta de la meitat Harijan del poble Kuthathi), qui va anunciar el veredicte al final de la festa, comunicant a l'assemblea I'opinió dels déus sobre la puresa i la perfecció del ritual acomplert.

Aquests elements mostren bé, al meu parer, que hi ha un únic culte religiós, que uneix les castes baixes i les altes, en aquesta regió.

Malgrat la seva influència recíproca, el món còsmic i el món social no poden posarse en paral·lel, car fins i tot les seves estructures no s'assemblen gaire: mentre que el món dels homes està dividit en categories fixes i rígides ${ }^{23}$, el món de les entitats sobrenaturals es caracteritza per la fluïdesa, la plasticitat. Els devta no es distingeixen pràcticament pas entre ells, ni a nivell de la iconografia ni a nivell biogràfic o mitològic: les seves històries són tot sovint imprecises, confuses, desconegudes o ignorades, i les seves representacions es limiten de vegades a un simple munt de tridents, mentre que les petites cares de metall (mohra) que adornen els seus palanquins (rath) són totes idèntiques. Les seves competències no tenen res de fix, ja que les poden guanyar o perdre jugant a daus entre ells, però els poden igualment perdre per culpa dels humans ${ }^{24}$; la seva definició depèn del punt de vista de cada individu (segons que és de casta baixa o alta, vegetarià o no) i des d'un punt de vista geogràfic (segons si estem parlant d'un sol poble o d'una regió). La frontera entre aquestes divinitats locals i les entitats malèvoles (bhut), encara que estigui una mica més marcada, no és tampoc molt estanca: cap és totalment bo o dolent, i cadascun pot a més canviar ontològicament, els devta esdevenint bhut i a la inversa. Quant a la relació entre els déus generals del panteó hindú i les divinitats locals, hem vist que es caracteritza per l'ambigüitat, i que les últimes són simultàniament inferiors i iguals als primers, fins i tot englobant- $\operatorname{los}^{25}, \mathrm{i}$

\footnotetext{
${ }^{23}$ Encara que la jerarquia de les castes sigui relativa i tot sovint difícil d'establir, les castes en elles mateixes són tancades i aquesta frontera és gairebé irrompible.

24 "Pendant les séances de possession, la sécheresse était également présentée comme une perte du pouvoir des dieux qui, par leur gur, disaient souvent "Vous avez perdu la vérité, nous avons perdu le pouvoir." Le comportement actuel des hommes faisait qu'ils ne possédaient plus les pouvoirs d'antan en particulier la pluie". (Berti 2001: 262)

${ }^{25}$ Vegeu més amunt en aquest article
} 


\section{perifèria}

Número 9, Diciembre 2008

www.periferia.name

que un petit devta Harijan pot al mateix temps ser una d'aquestes divinitats centrals del panteó hindú.

Un segon punt que sorgeix del treball de camp és la importància de considerar cada poble no com una unitat separable sinó com un membre d'un organisme viu. Aquest organisme és, en el nostre estudi, el conjunt dels vint-i-tres pobles sota la jurisdicció del devta Śeş Nag. Cada casta necessita les altres castes en la vida quotidiana (encara que sigui només a nivell ritual i simbòlic), i necessita els altres segments de la mateixa casta situats en els pobles veins (per algunes unions matrimonials per exemple). Si en altres regions de l'Índia les castes (altes i baixes) s'agrupen sovint en el mateix poble (però repartides en diferents zones del poble), en el cas de la regió estudiada les castes estan separades en diferents petits poblets (cadascun dels quals tenen una era de batre, un nom propi i un déu propi, així que els podem considerar com a poblets), agrupant d'un costat les castes altes i d'un altre les castes baixes (a l'excepció d'un poble on la meitat és Rajput i l'altre meitat és Harijan). Ara bé, les castes són uns elements d'un sistema, i no poden, doncs, estar conceptualment separades. A més, els diferents "servidors" del devta Śeş Nag estan repartits entre les castes i sobretot entre els diferents pobles ${ }^{26}$. A continuació, els devta manifesten una forta activitat a dins d'aquest perímetre, i cada dia es senten els tambors d'una o altra divinitat que es desplaça cap a un altre d'aquests vint-i-tres pobles. Aquesta constatació d'una unitat es recolza també sobre un sentiment de conjunt que és palpable entre els pobletans, i que es resumeix principalment en dos tipus de comentaris: d'una banda alguns comentaris evocant una forta solidaritat i defensa mútua entre els vint-i-tres pobles, d'una altra les descripcions del sistema cultural afirmant que hi ha un únic devta (Śeş Nag) i un únic gur per a aquest conjunt de pobles, qualificant aquest devta de "Primer ministre" mentre que els altres déus que resideixen sobre el seu territori són "soldats". La continuació de la investigació ens mostrarà si l'economia i l'organització social participen també d'aquest organisme viu.

26 Aquests servidors són el gur, el Pujari (sacerdot), els quatre Kardar (managers), el Maddhari (guarde), els artesans i els músics. 


\section{perifèria}

Número 9, Diciembre 2008

www.periferia.name

\section{Bibliografía}

Baechler, J. (1988). La solution indienne: essai sur le régime des castes, Paris: Presses Universitaires de France.

Berti, D. (1999). Un dieu maître-chanteur. La résolution d'un conflit villageois dans la vallée de Kullu (Himachal Pradesh), a Assayag, J. i Tarabout, G. (dir.), La possession en Asie du Sud (parole, corps, territoire), Paris: EHESS, Collection Puru ārtha 21, pp. 61-97.

Berti, D. (2001). La parole des dieux, rituels de possession en Himalaya indien, Paris: CNRS éditions.

Census of India 2001:

http://www.censusindia.gov.in/Census_Data_2001/India_at_glance/religion.aspx

Deliège, R. (2006). Le système indien des castes, Villeneuve d'Ascq: Presses Universitaires du Septentrion.

Dumont, L. (1957). Une sous-caste de I'Inde du Sud. Organisation sociale et religion des Pramalai Kallar, Paris - La Haya : Mouton.

Dumont, L. (1966). Homo Hiérarchicus, Le système des castes et ses implications, Paris: Gallimard.

Favret-Saada, J. (1977). Les mots, la mort, les sorts, Paris: Gallimard.

Hamayon, R. (1995). "Are "Trance", "Ecstasy" and Similar Concepts Appropriate in the Study of Shamanism?", a K. Tae-Gon i M. Hoppàl (ed.), Shamanism in Performing Arts, Budapest: Akadémiai Kiadó.

Krengel, M. (1999). "Spirit possession in the central Himalayas. Jāgar-rituals : an expression of the customs and rights", a Assayag, J. i Tarabout, G. (dir.), La possession en Asie du Sud (parole, corps, territoire), Paris: EHESS, Collection Puru ārtha 21, pp. 265-288.

Lewis, I.M. (1989). Ecstatic Religion, a Study of Shamanism and spirit possession, London - New-York: Routledge. 


\section{perifèria}

Número 9, Diciembre 2008

www.periferia.name

Mastromattei, R. (1988). La terra reale. Dèi spiriti, uomini in Nepal, Roma: Valerio Levi.

Mayaram, S. (1999). Spirit possession, reframing discourses of the Self and Other, a Assayag, J. i Tarabout, G. (dir.), La possession en Asie du Sud (parole, corps, territoire), Paris: EHESS, Collection Puru ārtha 21, pp.101-131.

Olivier de Sardan, J-P (2002). Possession in Bonte-Izard, Dictionnaire de l'ethnologie et de l'anthropologie, Paris: PUF, pp. 594-596.

Tarabout, G. (1999). Prologue, a Assayag, J. i Tarabout, G. (dir.), La possession en Asie du Sud (parole, corps, territoire), Paris: EHESS, Collection Puru ārtha 21, pp. 9-25.

Tarabout, J. i Assayag, G. (dir.) (1999). La possession en Asie du Sud (parole, corps, territoire), Paris: EHESS, Collection Puru ārtha 21.

Tardan-Masquelier, Y. (1999). L'hindouisme. Des origines védiques aux courants contemporains, Paris: Bayard.

Uchiyamada, Y. (1999). Soil, self, resistance: late-modernity and locative spirit possession in Kerala, a Tarabout, J. i Assayag, G. (dir.), La possession en Asie du Sud (parole, corps, territoire), Paris: EHESS, Collection Puru ārtha 21, pp. 289311.

Vidal, D. (1989). Le culte des divinités locales dans une région de l'Himachal Pradesh, Paris: Orstom. 